\title{
Fine-Grained Lexical Semantic Representations and Compositionally-Derived Events in Mandarin Chinese
}

\author{
Jimmy Lin \\ MIT Computer Science and Artificial Intelligence Laboratory \\ Cambridge, MA 02139 \\ jimmylinecsail.mit.edu
}

\begin{abstract}
Current lexical semantic representations for natural language applications view verbs as simple predicates over their arguments. These structures are too coarse-grained to capture many important generalizations about verbal argument structure. In this paper, I specifically defend the following two claims: verbs have rich internal structure expressible in terms of finer-grained primitives of meaning, and at least for some languages, verbal meaning is compositionally derived from these primitive elements. I primarily present evidence from Mandarin Chinese, whose verbal system is very different from that of English. Many empirical facts about the typology of verbs in Mandarin cannot be captured by a "flat" lexical semantic representation. These theoretical results hold important practical consequences for natural language processing applications.
\end{abstract}

\section{Introduction}

Lexical semantics is becoming increasingly important in a variety of natural language applications from machine translation to text summarization to question answering. Since it is generally agreed that the verb is the locus of "meaning" in a natural language sentence, theories of verbal argument structure are extremely important for our understanding of lexical semantics.

An appropriate lexical semantic representation can illuminate difficult problems in language processing, expose facets of meaning relevant to the surface realization of sentential elements, and reveal insights about the organization of the human language faculty. In machine translation, a "good" representation of verbs can straightforwardly capture cross-linguistic divergences in the expression of arguments. In question answering, lexical se- mantics can be leveraged to bridge the gap between the way a question is asked and the way an answer is stated.

This paper explores fine-grained lexical semantic representations-approaches that view a verb as more than a simple predicate of its arguments (e.g., Dang et al., 2000). This contrasts with recent semantic annotation projects such as PropBank (Kingsbury and Palmer, 2002) and FrameNet (Baker et al., 1998). For example, while it is undeniable that throw(John, the ball, Mary), is a valid representation for the sentence "John threw the ball to Mary", it is widely believed (at least by theoretical linguists) that decomposing verbs in terms of more basic primitives can better capture generalizations about verb meaning and argument realization. I will argue that finer-grained semantics is not only theoretically motivated, but necessary for building applications.

I first provide a brief overview of theories of verbal argument structure, and then contrast the typology of Mandarin verbs with that of English verbs. I will present evidence from Chinese that verb meaning is compositionally "built up" from primitive notions of stativity and activity. The consequence, therefore, is that "flat" representations lacking internal structure are unable to capture the verbal semantics of a language like Mandarin. Productive phenomena such as verbal compounding render enumeration of all permissible verbs impossible. Verb meaning, therefore, must be represented decompositionally in terms of underlying primitives. This paper does not propose a concrete lexical semantic representation, but rather focuses on the requirements, for natural language applications, of such a representation.

\section{Event Types}

The earliest theory of verbal argument structure involves generalized collections of semantic roles, known as a case frame (Fillmore, 1968) or a theta-grid (Stowell, 1981) under the framework of Government and Binding Theory. The idea of semantic roles was first explicated 
in Fillmore's seminal paper, "The Case for Case" (1968), which argues that the propositional component of a sentence can be represented as an array consisting of the verb and a number of noun phrases specifically marked with roles such as agent, patient, instrument, and goal. These labels identify the grammatically relevant aspects of the roles that pertain to argument realization in the syntax. A verb is defined by the semantic roles that it "takes", i.e., its case frame. For example, love takes an agent and a patient, while frighten takes an experiencer and a stimulus.

A theory of argument structure is not complete without an associated linking theory that explicitly maps arguments in the lexical semantic representation (semantic roles) to syntactic arguments. Approaches based on semantic roles often formulate a linking theory in terms of a thematic hierarchy (Jackendoff, 1972): semantic roles are arranged in an abstract "prominence" hierarchy, and the realization of syntactic arguments is based on the position of roles in this hierarchy. The highest role in the thematic hierarchy is assigned the highest argument position in the syntactic structure (the subject), the next highest role is assigned the next highest argument, and so forth. Thematic hierarchies are believed to be an independent and irreducible module of grammar.

There has been considerable debate over the ordering of roles on thematic hierarchies. In fact, the actual inventory of semantic roles, along with precise definitions and diagnostics, remains an unsolved problem. These are not the only drawbacks associated with theories of argument structure that rely on semantic roles: ${ }^{1}$ Some analyses show that semantic roles are too coarse-grained to account for certain semantic distinctions. The only recourse, to expand the collection of roles, comes with the price of increased complexity, e.g., in the linking rules. Fillmore's original assumption that each noun phrase in an utterance occupies a unique thematic role is often called into question. For some verbs, e.g., resemble, multiple noun phrases appear to have the same semantic role. Finally, because case frames are "flat", i.e., lacking any internal structure, a theory based purely on semantic roles lacks real explanatory power. Why is it, for example, that love takes an obligatory agent and an obligatory patient? Why is the instrument role in open optional? These theories cannot offer satisfactory answers because they do not directly refer to the meaning of predicates.

Recognizing the drawbacks of theories based purely on semantic roles, there is now a general consensus among linguists that argument structure is (to a large extent) predictable from event semantics-hence, patterns of argument realization should be inferable from lexical semantic representations grounded in a theory of events. These event representations typically decompose seman-

\footnotetext{
${ }^{1}$ see (Dowty, 1991) and (Levin and Rappaport Hovav, 1996)
}

tic roles in terms of primitive predicates representing concepts such as causality, agentivity, inchoativity, and stativity (Dowty, 1979; Jackendoff, 1983; Pustejovsky, 1991b; Rappaport Hovav and Levin, 1998).

\section{From Event Types to Event Structure}

Although Aristotle (Metaphysics 1048b) observed that the meanings of some verbs involve an "end" or a "result", and other do not, it wasn't until the twentieth century that philosophers and linguists developed a classification of event types which captures logical entailments and the co-occurrence restrictions between verbs and other syntactic elements such as tenses and adverbials. Vendler's (1957) classification of events into states, activities, accomplishments, and achievements is groundbreaking in this respect. In his event ontology, activities and states both depict situations that are inherently temporally unbounded (atelic); states denote static situations, whereas activities denote on-going dynamic situations. Accomplishments and achievements both express a change of state, and hence are temporally bounded (telic); achievements are punctual, whereas accomplishments extend over a period of time. Examples of the four event types are given below:

$\begin{array}{lll} & \text { States } & \text { Activities } \\ \text { know } & \text { run } \\ \text { believe } & \text { walk } \\ \text { desire } & \text { push a cart } \\ \text { Accomplishments } & \text { Achievements } \\ \text { paint a picture } & \text { recognize } \\ \text { make a chair } & \text { find } \\ \text { deliver a sermon } & \text { lose }\end{array}$

Although activities group naturally with states and accomplishments with achievements in terms of telicity, it has also been observed that states can be grouped with achievements and activities with accomplishments in that that first pair lacks the progressive tense, while the second pair allows them (cf. Lakoff, 1966; Shi, 1988). To capture these properties, Vendler's classes can be further decomposed in terms of independent features (cf. Andersen, 1990; Van Valin and LaPolla, 1997:91-102):
a. State: [-telic, -durative, -dynamic]
b. Activity: [-telic, +durative, +dynamic]
c. Achievement: [+telic, -durative +dynamic $]$
d. Accomplishment: [+telic, +durative +dynamic]

Vendler's work on ontological types of events serves as a foundation upon which others have grounded lexical semantic representations and theories of verbal argument structure. Dowty's seminal work (1979) attempts 
to decompose states, activities, accomplishments, and achievements in terms of the primitives DO, CAUSE, and BECOME:

$$
\begin{aligned}
& \text { a. state: } \pi_{n}\left(\alpha_{1}, \ldots, \alpha_{n}\right) \\
& \text { b. activity: } \operatorname{DO}\left(\alpha_{1},\left[\pi_{n}\left(\alpha_{1}, \ldots, \alpha_{n}\right)\right]\right) \\
& \text { c. achievement: } \operatorname{BECOME}\left[\pi_{n}\left(\alpha_{1}, \ldots, \alpha_{n}\right)\right] \\
& \text { d. accomplishment: } \\
& \quad\left[\left[\operatorname{DO}\left(\alpha_{1},\left[\pi_{n}\left(\alpha_{1}, \ldots, \alpha_{n}\right)\right]\right)\right]\right. \text { CAUSE } \\
& \left.\quad\left[\operatorname{BECOME}\left[\pi_{n}\left(\alpha_{1}, \ldots, \alpha_{n}\right)\right]\right]\right]
\end{aligned}
$$

(Dowty, 1979:123-124)

Examples of Dowty's theory applied to English sentences are shown below:

$$
\begin{aligned}
& \text { a. He sweeps the floor clean. } \\
& {[[\text { DO }(\text { he }, \text { sweeps }(\text { the floor }))] \text { CAUSE }} \\
& [\text { BECOME }[\text { clean }(\text { the floor })]]] \\
& \text { b. John walks. } \\
& {[\text { DO(John, walk) }]}
\end{aligned}
$$

In what later becomes a standard analysis adopted by subsequent linguists, Dowty breaks causative sentences down into two subevents: a causing subevent and a result subevent. The representation of the resultative sentence (4a) is comprised of the causing subevent "he sweeps the floor" and the result subevent "the floor is clean". Unergative verbs, on the other hand, are represented by a single subevent with the primitive DO.

Rappaport Hovav and Levin's more recent theory of event templates (1998) also defines a basic inventory of event building blocks in terms of Vendler's event types:

$$
\begin{aligned}
& \text { a. }\left[x \mathrm{ACT}_{<M A N N E R>}\right] \text { (activity) } \\
& \text { b. }[x<\text { STATE }>](\text { state) } \\
& \text { c. }[\text { BECOME }[x<\text { STATE }>]] \text { (achievement) } \\
& \text { d. }[x \text { CAUSE }[\text { BECOME }[y<\text { STATE }>]]] \\
& \quad(\text { accomplishment) } \\
& \text { e. }[[x \text { ACT }<\text { MANNER }>\text { CAUSE }[\text { BECOME } \\
& \quad[y<\text { STATE }>]]] \text { (accomplishment) } \\
& \text { (Rappaport Hovav and Levin, 1998:108) }
\end{aligned}
$$

A verb's meaning consists of a constant paired with a particular event template drawn from the basic inventory above. Constants are open-class items drawn from a fixed ontology (e.g., manner, instrument, state, etc.) and are represented within the angle brackets of the event template. An important claim of this theory is that verbs directly encode, or lexicalize, complex event structures.

To account for complex events and secondary predication, Rappaport Hovav and Levin propose a process called Template Augmentation that allows basic event templates to be freely "augmented" to any other event template. This process, for example, explains the resultative form of surface contact verbs like sweep:
(6) a. Phil swept the floor.

[Phil $\mathrm{ACT}_{<\text {SWEEP }>}$ floor]

b. Phil swept the floor clean.

$\left[\right.$ [ Phil $\mathrm{ACT}_{<S W E E P>}$ floor $]$ CAUSE

$[$ BECOME $[$ floor $<C L E A N>]]]$

In this case, an activity has been augmented into an accomplishment through the addition of another subevent, i.e., the floor becoming clean (note similarities with Dowty's representation). In order to bring the lexical semantic representation "into alignment" with syntactic structure for the purpose of argument realization, Levin and Rappaport Hovav (1995) propose well-formedness constraints and linking rules such as the following:

a. Immediate Cause Linking Rule. The argument of a verb that denotes the immediate cause of the eventuality described by that verb is its external argument.

b. Directed change Linking Rule. The argument of the verb that corresponds to the entity undergoing the directed change described by that verb is its internal argument.

Vendler's ontology of verbal types has paved the way for many important developments in lexical semantics. Although the role of lexical aspect in argument realization has been called into question (Levin, 2000), this generally-accepted classification of events figures prominently in most theories of verbal argument structure. Of great interest both theoretically and for the purposes of building language applications, therefore, is the typological organization of verbal systems in different languages. Can Vendler's event type ontology, which was originally developed for English, be directly applied to other languages as well? The answer, I will demonstrate, at least for Mandarin Chinese, is no.

\section{The Mandarin Verbal System}

I will argue that the typology of Mandarin Chinese verbs is very different from that of English verbs. Specifically, I make the following claims:

a. Activity and state are the only two primitive verbal types in Mandarin Chinese. Accomplishments and achievements are derived compositionally.

b. With a small number of exceptions, there are no monomorphemic verbs in Mandarin that are telic-no monomorphemic verb necessarily encodes a result, an end state, or the attainment of a goal.

c. The particle $l e$, among other uses, signals inchoativity. 
The somewhat controversial claim that Mandarin lacks monomorphemic accomplishments and achievements has been previously made by a number of linguists, most notably Tai (1984); see also (Shi, 1988). These works serve as a starting point for my inquiry into the typological organization of Mandarin verbs.

One important bit of evidence is the existence of activity/achievement verb pairs in English, which are not present in Mandarin:

$\begin{array}{ll}\text { English } & \\ \text { activity } & \text { achievement } \\ \text { look (at) } & \text { see } \\ \text { listen (to) } & \text { hear } \\ \text { study } & \text { learn } \\ \text { look for } & \text { find }\end{array}$

\begin{tabular}{|c|c|}
\hline $\begin{array}{l}\text { Mandarin } \\
\text { activity }\end{array}$ & achievement \\
\hline$k_{a n} 4$ 'look' & $\begin{array}{l}\mathrm{kan}_{4} \mathrm{jian}_{4} \text { 'look-perceive' } \\
=\text { see }\end{array}$ \\
\hline ting $_{1}$ 'listen' & $\begin{array}{l}\text { ting }_{1} \text { jian }_{4} \text { 'listen-perceive' } \\
=\text { hear }\end{array}$ \\
\hline$x_{2} e_{2}$ 'study' & $\begin{array}{l}\text { xue }_{2} \text { hui }_{4} \text { 'study-able' } \\
=\text { learn }\end{array}$ \\
\hline$z_{h a o_{3}}$ 'look for' & $\begin{array}{l}\text { zhao }_{3} \mathrm{dao}_{4} \text { 'look.for-arrive' } \\
=\text { find }\end{array}$ \\
\hline
\end{tabular}

In English, for example, the verb look expresses an atelic activity, while the verb see expresses a telic achievement that lexicalizes the attainment of a goal (i.e., the successful act of perception). Mandarin Chinese, however, does not have monomorphemic counterparts for English achievements. To encode an end state, Chinese speakers must resort to resultative verb compounds, where the first verb denotes the activity, and the second verb denotes the result. For verbs of perception, two different result morphemes are typically used: jian 4 , best glossed as 'perceive', and $d \mathrm{o}_{4}$, literally 'arrive'.

The claim that resultative verb compounds are required to explicitly encode the result state is supported by the grammaticality of sentences that explicitly deny the attainment of the goal:

(11) $\mathrm{ta}_{1} \mathrm{kan}_{4} l e_{5} \mathrm{ban}_{4} \operatorname{tian}_{1}, \quad k e_{3} s h i_{4} \mathrm{mei}_{2}$
he look LE half day but not-have
$k a n_{4} \quad j i a n_{4}$
look perceive
'He looked for a long time, but couldn't see it.'

In contrast, using a resultative verb compound in the first clause triggers a contradiction:
(12) *ta kan $_{4}$ jian $_{4} \quad l e_{5}$ ban $_{4}$ tian $_{1}, \quad k e_{3} s h i_{4}$ he look perceive LE half day but
$\mathrm{mei}_{2} \quad \mathrm{kan}_{4} \mathrm{jian}_{4}$
not-have look perceive

intended: 'He saw for a long time, but couldn't see it.'

Another important bit of evidence comes from the interpretations of accomplishments. In English, accomplishments are compatible with both in and for adverbials, the standard diagnostic for telicity:
a. John wrote a letter for an hour.
b. John wrote a letter in a hour.

As demonstrated in the above example, writing a letter can be interpreted as either atelic (13a) or telic (13b). The atelic interpretation is to be understood as "John engaged in the activity of letter writing for an hour", whereas the telic interpretation implies the completion of the letter.

Both readings are generally available, but in the past tense, the telic accomplishment is much more salient. Thus, to deny the completion of the goal renders the sentence decidedly odd:

(14) \#John wrote a letter yesterday, but he didn't finish it.

It is, however, not very difficult to construct a context that renders the above sentence felicitous:

(15) John is always writing letters, but he never finishes any of them. In fact, John wrote a letter yesterday, but as usual, he didn't finish it.

The situation in Mandarin, however, is very different. It appears that the Chinese counterpart of write, $x_{i} e_{3}$, has no reading that necessarily implies completion of the direct object (incremental theme):

$$
\begin{array}{lllllll}
\text { (16) } \text { wo }_{3} & \text { zou }_{2} \text { tian }_{1} & \text { xie }_{3} & \text { le } & \text { yi } & \text { feng } & \text { xin } \\
\text { I } & \text { yesterday } & \text { write } & \text { LE } & \text { one } & \mathrm{CL} & \text { letter } \\
\mathrm{Ie}_{3} \mathrm{shi}_{4} & \text { mei }_{2} & \mathrm{xi}_{3} & \text { wan }_{2} & & \\
\text { but } & \text { not-have } & \text { write } & \text { finish } & \\
\text { 'I wrote a letter yesterday, but I didn't finish it.' }
\end{array}
$$

In fact, the only way to encode completion of the letter writing is, once again, through a resultative verb compound such as $\mathrm{xie}_{3} \mathrm{wan}_{2}$ 'write-finish'.

I have thus far demonstrated that the Mandarin equivalent of many English verbs cannot be expressed monomorphemically, but rather must involve a verbal compound. In order to defend my claims, however, the following (apparent) counterexamples must be explained:
a. $\mathrm{sh}_{4} \mathrm{dao}_{3} \quad l e_{5}$
tree fall LE
'The tree fell.'
b. bo $_{1} \mathrm{li}_{2} \mathrm{sui}_{4} \quad l e_{5}$ glass shatter LE 'The glass shattered.' 
It appears that $d_{a o_{3}}$ and $\mathrm{sui}_{4}$ are monomorphemic verbs that express change of state. In order for my claims to be correct, I would have to demonstrate that such verbs are actually derived from more basic forms. Indeed, this is the case: the examples above are derived from underlying stative predicates - the particle le signals inchoativity.

The following stative/inchoative minimal pair presents evidence for my theory:
a. $\mathrm{shu}_{4} \quad \mathrm{gao}_{1} \quad \mathrm{shi}_{2} \quad \mathrm{gung}_{1} \mathrm{fen}_{1}$
tree tall ten centimeter
'The tree is ten centimeters tall.'
b. shu $_{4} \quad$ gao $_{1}$ le $_{5} \quad$ shi $_{2} \quad$ gung $_{1}$ fen $_{1}$
tree tall LE ten centimeter
'The tree grew ten centimeters.'

The only difference in the two above sentences is the presence/absence of $l e$. The particle, therefore, must contribute the semantic component of inchoativity. Similar minimal pairs related to prenominal modifiers show this same contrast:

$$
\begin{aligned}
& \begin{array}{lll}
\text { a. } \text { sui }_{4} \quad\left(d e_{5}\right) & \text { bo }_{1} l i_{2} \\
\text { shattered } & \text { DE } & \text { glass }
\end{array} \\
& \text { 'shattered glass' (stative/adjective) } \\
& \text { b. } \text { sui }_{4} \quad l e_{5} \quad d e_{5} \quad b o_{1} l i_{2} \\
& \text { shattered } \quad \text { LE } \quad \text { DE } \quad \text { glass } \\
& \text { 'glass that was shattered' (resultative } \\
& \text { participle) }
\end{aligned}
$$

The above pair represents a subtle but detectable difference in meaning; whereas (19a) describes a pure state, (19b) describes the result of an event. This distinction exactly parallels the difference between an open door and an opened door in English. Once again, since the sentences differ only by $l e$, the particle must be contributing that semantic component. As further evidence, consider the following minimal pair:

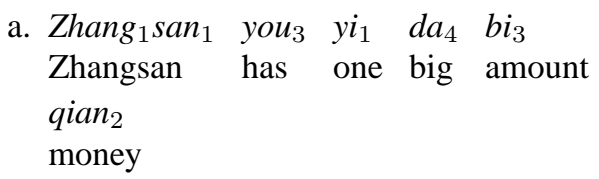

'Zhangsan has a lot of money.'

b. $Z_{\text {hang }} \operatorname{san}_{1} \quad$ you $_{4} \quad l e_{5} \quad y i_{1} \quad d a_{4} \quad b i_{3}$ Zhangsan has LE one big amount qian $_{2}$ money

'Zhangsan has acquired a lot of money.'

Once again, the addition of le creates a change of state acquire out of a simple stative predicate have. The semantic contribution of the particle $l e$ is also seen in a subordinate clause:
(21)
a. wo $_{3}$ kan $_{4}$ jian $_{4} \quad \mathrm{shu}_{4}$ dao $_{3}$ zhai $_{4}$ I see perceive tree fall at $\mathrm{lu}_{4}$ bian $_{1}$ road side 'I see the fallen tree at the side of the road.' (tree may have fallen a long time ago)

b. $\begin{array}{lllllll}\text { wo }_{3} & \text { kan }_{4} & \text { jian }_{4} & \text { shu }_{4} & \text { dao }_{3} & \text { le } & \text { zhai }_{4}\end{array}$ I see perceive tree fall $\mathrm{LE}$ at $\mathrm{lu}_{4} \mathrm{bian}_{1}$ road side

'I see the tree falling at the side of the road.' (eye witness account)

Once again, the stative reading is contrasted with the change of state reading. The interpretation of the above two sentences is consistent with the analysis of $l e$ as a signal of inchoativity.

It is clear from the above minimal pairs that the particle le combines with stative predicates to gives rise to change of state interpretations. Are these derived events achievements or accomplishments? Dowty (1979) provides the following diagnostics:

$\begin{array}{lll} & \text { compatible with } & \text { complement } \\ & \text { progressive? } & \text { of stop } \\ \text { state } & \text { no } & \text { ok } \\ \text { activity } & \text { yes } & \text { ok } \\ \text { accomplishment } & \text { yes } & \text { ok } \\ \text { achievement } & \text { maybe } & \text { bad }\end{array}$

Accomplishments are generally compatible with the progressive; some achievements appear felicitous (e.g.,

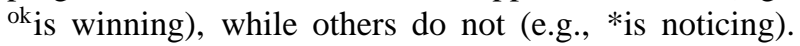
Accomplishments, since they are durative, are generally acceptable as the complement of stop, whereas the punctual nature of achievements renders them ungrammatical. These diagnostics clearly demonstrate that the addition of le shifts stative predicates into achievements:

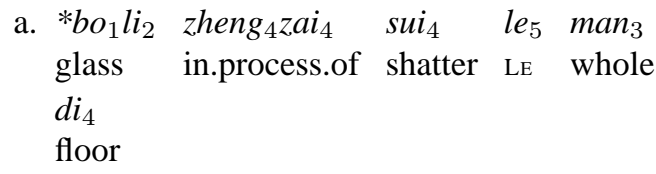
shattering all over the floor.'

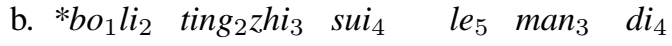
glass stop shatter LE whole floor intended: 'The glass stopped shattering all over the floor.'

It is interesting to note that many achievements in Mandarin cannot directly causativize into the transitive form: 


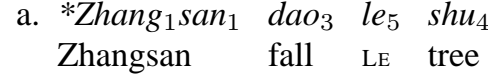

intended: 'Zhangsan fell the tree.'

b. ??Zhang san $_{1}$ sui $_{4} \quad l e_{5}$ bo $_{1} l_{2}$

Zhangsan shatter LE glass

intended: 'Zhangsan shattered the glass.'

Instead, a resultative verb compound is necessary to express an accomplishment. Typically, the second verb denotes the result (end state) of the event, while the first verb denotes the activity that brings about the end state:

a. Zhang $\operatorname{san}_{1} \mathrm{kan}_{3} \mathrm{dao}_{3} \mathrm{le}_{5} \quad \mathrm{shu}_{4}$ Zhangsan chop fall Le tree

'Zhangsan chopped the tree down.'

b. Zhang San $_{1} \quad \mathrm{da}_{3} \mathrm{sui}_{4} \quad l e_{5} \quad$ bo $_{1} \mathrm{li}_{2}$ Zhangsan hit shatter LE glass

'Zhangsan shattered the glass.'

Putting all the pieces together, the organization of the Mandarin verbal system can be summarized as follows:

(26) primitive event types: activity, state

state $+l e \rightarrow$ achievement

activity + achievement $\rightarrow$ accomplishment

Activity and state are the two primitive verbal categories in Mandarin. Non-causative change of state predicates (achievements) are derived from states with the addition of the particle le. Accomplishments are further derived from achievements through the formation of resultative verb compounds in which the first verb denotes an activity, and the second verb the end state.

Traditionally, the particle $l e$ that appears post-verbally has been analyzed as an aspectual marker denoting perfectivity ( $\mathrm{Li}$ and Thompson, 1981). This contrasts with my analysis of it as a signal of inchoativity. How are these two approaches to be reconciled? In (Lin, 2004b), I argue that $l e$ is a reflex, rather than an overt realization of the underlying inchoative marker. As generally defined, perfective aspect is not compatible with stative predicates. However, the addition of a covert inchoative functional head, in effect, licenses the perfective aspect.

\section{Computational Significance?}

Why is this peculiar organization of the Mandarin verbal system important for lexical semantic representations designed for language applications? It demonstrates that, at least for languages such as Mandarin Chinese, the verb phrase must be rich in internal structure; a verb cannot be simply viewed as a predicate of its arguments. Evidence from Mandarin resultative verb compounds demonstrate that verbal predicates themselves must be compositionally built from underlying primitives.
It is important to note that the formation of verbal compounds in Chinese is a fully productive process - the only constraint on verb combinations appears to stem from plausible real-world associations between cause and effect. The following shows but a small range of possible resultative verb compounds with the $d a o_{3}$ 'fall' result:

$\begin{array}{cll}\text { (27) } \mathrm{kan}_{3} \mathrm{dao}_{3} & \text { chop-fall } & \text { to chop down } \\ \mathrm{zhuang}_{4} \mathrm{dao}_{3} & \text { crash-fall } & \text { to knock over } \\ \text { tui }_{1} \mathrm{daO}_{3} & \text { push-fall } & \text { to push over } \\ \mathrm{la}_{1} \mathrm{daO}_{3} & \text { pull-fall } & \text { to pull down }\end{array}$

In principle, verbal compound formation in Mandarin could be a lexical process, but I present elsewhere independent evidence for a non-lexicalist approach that captures these constraints in the theoretical framework of Distributed Morphology, an extension of Chomsky's Minimalist Program (Lin, 2004a; Lin, 2004b). However, the actual machinery for formalizing these insights is not important for the present discussion. The important lessons are the theoretical constraints imposed by verbal typology on lexical semantic representations designed for language applications. More specifically:

a. verbs have rich internal structure expressible in terms of finer-grained primitives of meaning, and

b. at least for some languages, verbal meaning is compositionally derived from these primitive elements.

These claims imply that a PropBank or FrameNet approach to lexical semantics will not be sufficient for many language applications, at least for languages such as Mandarin Chinese. While I may disagree with the technical details, I believe that the approach taken by (Dang et al., 2000) is on the right path. Due to the productivity of verbal phenomena in Mandarin, it is impossible to exhaustively enumerate all felicitous predicatesverbal meaning, therefore, must be compositionally derived from primitive elements. This however, does not mean that PropBank or FrameNet are not useful; quite the contrary! Existing semantic resources serve as the foundation from which we can bootstrap finer-grained semantic representations.

While the approach Palmer and Wu (1995) take to lexical semantics captures many selectional restrictions and finer-grained facets of meaning, it still does not model the arbitrary productivity of verbal compounds. For the purposes of translating English change of state verbs into Mandarin, they developed a conceptual lattice that unifies verbs from both languages. Distances between nodes in this lattice correspond to "semantic distance", and is used to find the closest translation if a specific meaning is unavailable. Although this approach results in better lexical selection, the semantic lattice still assumes that all 
verbal forms can be exhaustively enumerated. Although this certainly may be true within the context of a specific corpus, the productivity of Mandarin verbal phenomena is limitless in the real world.

I believe that, for all languages in general, verbal meanings are compositionally built up from states and activities. Furthermore, this process is syntactic in nature (Lin, 2004b), governed by well-known syntactic processes such as MERGE (Chomsky, 1995) and subjected to well-studied constraints such as selectional restrictions and the Head Movement Constraint (Travis, 1984). This contrasts with Rappaport Hovav and Levin's (1998) "event template" approach, which is lexicalist in that large chunks of event structure are directly associated with verbs. Under their analysis, the lexical entry associated with sui $_{4}$ 'shatter' would be something like:

(29) $\mathrm{sui}_{4}$ 'shatter' =

$\left[\left[x \mathrm{ACT}_{<U N D E F>}\right]\right.$ CAUSE $[\mathrm{BECOME}$

$[x<$ SHATTERED $>]]]$

Rappaport Hovav and Levin's theory argues that a verb's meaning is composed of an event template that captures the structural component of meaning and openclass constants that capture the idiosyncratic component of meaning (represented by items in angle brackets). This separation is a major breakthrough in lexical semantic theories because it allows grammatically relevant facets of meaning to be untangled from facets of meaning not directly relevant to the encoding of arguments. Descriptively, the structural component of meaning is what a verb shares with other verbs in the same verb class, whereas the idiosyncratic component of meaning is what separates verbs within the same verb class.

In Rappaport Hovav and Levin's account of verbal argument structure, complex event representations are directly introduced in the syntax; that is, the verb lexicalizes a complete causative accomplishment-to shatter implicates an agent participating in an unspecified activity that brings about a change of state where an entity becomes shattered. In English, they propose that intransitive verbs are derived by a process of "decausativization" through which the external argument is "absorbed", and therefore remains unexpressed (Levin and Rappaport Hovav, 1995). Such a theory is unable to account for the derivation of Mandarin resultatives such as $d a_{3} s u i_{4}$ 'hitshatter'. If (29) is indeed the representation of $s u i_{4}$ 'shatter', then what is the lexical semantic representation of $d a_{3}$ 'hit'? There are, in principle, two alternatives:

(30) Option 1: $d a_{3}$ 'hit' $=\left[x \mathrm{ACT}_{<H I T>}\right]$

Option 2: $d a_{3}$ 'hit' $=<H I T>$

One might suggest that $d a_{3}$ 'hit' is associated with its own event template that somehow gets merged with the lexical entry of $s u i_{4}$ 'shatter'. In order for this approach to be tenable, one has to explicate the process by which verbs are "fused" (and in many cases, how arguments of both verbs are sometimes merged or remain unexpressed); Li (1990) provides exactly such a lexical account, although it has been found to be problematic for many cases (Cheng and Huang, 1994). The other option is to suggest that $d a_{3}$ 'hit' merely encodes the idiosyncratic component of meaning, without an associated event template. This, however, cannot be true because $d a_{3}$ 'hit' itself can be used as a main verb:

\section{(31) $Z_{\text {hang }}$ san $_{1} \quad d a_{3} \quad l e_{5} \quad b_{1} l_{2}$ Zhangsan hit LE glass \\ 'Zhangsan hit the glass.'}

The only plausible solution is that verbs encode small fragments of event structure, which are compositionally built up by regular syntactic processes. This approach also provides a natural solution for handling verbs that are derivationally related to other lexical categories, e.g., deadjectival verbs such as flatten, widen, modernize, and legalize. These derivational affixes obviously contribute the inchoative component of meaning that turns states (adjectives) into change of states:

$$
\begin{aligned}
& \text { (32) flat: }[\text { state flat }] \\
& \text {-en: } \lambda s \lambda x \cdot \operatorname{BECOmE}(x, \operatorname{BE}(s)) \\
& \text { flat-en: } \lambda x \cdot \operatorname{BEcome}(x, \operatorname{BE}([\text { state flat }]))
\end{aligned}
$$

In such a treatment, for example, the complete semantics of a word can be compositionally derived from its component morphemes. This framework, where the "semantic load" is spread more evenly throughout the lexicon to lexical categories not typically thought to bear semantic content, is essentially the model advocated by Pustejovsky (1991a), among others. Such an analysis of verbal phenomena marks a departure from the standard architectural view of morphological analysis as a preprocessor-instead, morphological and syntactic derivation can be integrated under a common framework.

\section{Conclusion}

The key claim of this paper is that results from the theoretical study of verbal argument structure are relevant to computational lexical semantic representations for language applications. Although the simplest possible argument representation treats verbs as predicates over their arguments, I have demonstrated that this approach is woefully inadequate for handling a language such as Mandarin Chinese. I have presented evidence that verb meaning in Mandarin is compositionally built up from underlying state and activity primitives - this organization of the verbal system must be mirrored by any lexical semantic representation aspiring to capture generalizations about argument realization patterns. This paper 
takes an important step in laying out some of the constraints for such a representation.

\section{References}

Roger W. Andersen. 1990. Papiamentu tense-aspect, with special attention to discourse. In J. V. Singler, editor, Pidgin and Creole Tense-Mood-Aspect Systems, pages 59-96. John Benjamins, Amsterdam, The Netherlands.

Collin F. Baker, Charles J. Fillmore, and John B. Lowe. 1998. The Berkeley FrameNet project. In Proceedings of the 36th Annual Meeting of the Association for Computational Linguistics and 17th International Conference on Computational Linguistics (COLING/ACL 1998).

Lisa Lai-Shen Cheng and C.-T. James Huang. 1994. On the argument structure of resultative compounds. In Matthew Chen and Ovid Tzeng, editors, In honor of William S.-Y. Wang Interdisciplinary Studies on Language and Language Change, pages 187-221. Pyramid Press, Taipei, Taiwan.

Noam Chomsky. 1995. The Minimalist Program. MIT Press, Cambridge, Massachusetts.

Hoa Trang Dang, Karin Kipper, and Martha Palmer. 2000. Integrating compositional semantics into a verb lexicon. In Proceedings of the 18th International Conference on Computational Linguistics (COLING 2000).

David Dowty. 1979. Word Meaning and Montague Grammar. D. Reidel Publishing Company, Dordrecht, The Netherlands.

David Dowty. 1991. Thematic proto-roles and argument selection. Language, 67(3):547-619.

Charles J. Fillmore. 1968. The case for case. In E. Bach and R. Harms, editors, Universals in Linguistic Theory, pages 1-88. Holt, Rinehart, and Winston, New York.

Ray Jackendoff. 1972. Semantic Interpretation in Generative Grammar. MIT Press, Cambridge, Massachusetts.

Ray Jackendoff. 1983. Semantics and Cognition. MIT Press, Cambridge, Massachusetts.

Paul Kingsbury and Martha Palmer. 2002. From TreeBank to PropBank. In Proceedings of the Third International Conference on Language Resources and Evaluation (LREC-2002).

George Lakoff. 1966. Stative adjectives and verbs in English. NSF-Report 17, Harvard Computational Laboratory.

Beth Levin and Malka Rappaport Hovav. 1995. Unaccusativity: At the Syntax-Lexical Semantics Interface, volume 26 of Linguistic Inquiry Monograph. MIT Press, Cambridge, Massachusetts.
Beth Levin and Malka Rappaport Hovav. 1996. From lexical semantics to argument realization. Unpublished manuscript, Northwestern University and Bar Ilan University.

Beth Levin. 2000. Aspect, lexical semantic representation, and argument expression. In Proceedings of the 26th Annual Meeting of the Berkeley Linguistics Society.

Charles N. Li and Sandra A. Thompson. 1981. Mandarin Chinese: A Functional Reference Grammar. University of California Press, Berkeley, California.

Yafei Li. 1990. On V-V compounds in Chinese. Natural Language and Linguistic Theory, 9:177-207.

Jimmy Lin. 2004a. A computational framework for non-lexicalist semantics. In Proceedings of the 2004 HLT/NAACL Student Research Workshop.

Jimmy Lin. 2004b. Event Structure and the Encoding of Arguments: The Syntax of the English and Mandarin Verb Phrase. Ph.D. thesis, Department of Electrical Engineering and Computer Science, Massachusetts Institute of Technology.

Martha Palmer and Zhibiao Wu. 1995. Verb semantics for English-Chinese translation. IRCS Report 95-22, Institute for Research in Cognitive Science, University of Pennsylvania.

James Pustejovsky. 1991a. The generative lexicon. Computational Linguistics, 17(4):409-441.

James Pustejovsky. 1991b. The syntax of event structure. Cognition, 41:47-81.

Malka Rappaport Hovav and Beth Levin. 1998. Building verb meanings. In Miriam Butt and Wilhelm Geuder, editors, The Projection of Arguments: Lexical and Compositional Factors. CSLI Publications, Stanford, California.

Ziqiang Shi. 1988. The Present of Past of the Particle Le in Mandarin Chinese. Ph.D. dissertation, University of Pennsylvania.

Tim Stowell. 1981. Elements of Phrase Structure. Ph.D. thesis, Massachusetts Institute of Technology.

James H-Y. Tai. 1984. Verbs and times in chinese: Vendler's four categories. In David Testen, Veena Mishra, and Joseph Drogo, editors, Papers from the Parasession on Lexical Semantics. Chicago Linguistic Society, Chicago, Illinois.

Lisa Travis. 1984. Parameters and Effects of Word Order Variation. Ph.D. dissertation, Massachusetts Institute of Technology, Department of Linguistics.

Robert D. Van Valin and Randy J. LaPolla. 1997. Syntax. Structure, Meaning and Function. Cambridge University Press, Cambridge, England.

Zeno Vendler. 1957. Verbs and times. Philosophical Review, 56:143-160. 